\title{
Da fome à palatabilidade estéril: 'espessando' ou 'diluindo' o Direito Humano à Alimentação Adequada no Brasil?
}

\author{
From hunger to sterile palatability: 'thickening' or 'diluting' the \\ Human Right to Adequate Food in Brazil?
}

Lúcia Dias da Silva Guerra', Aída Couto Dinucci Bezerra², Leonardo Carnut³

DOI: 10.1590/0103-1104202012721

RESUMO No cenário contemporâneo, a tríade 'alimento-mercadoria-doença' se 'espessa' e se 'dilui' em virtude dos rearranjos das crises econômicas globais e suas expressões locais na dinâmica política-econômica-social capitalista. Reproduzindo-se em suas diferentes faces: a da escassez - fome, desnutrição, carências nutricionais; e a dos problemas advindos do excesso de consumo de alimentos altamente industrializados - sobrepeso, obesidade e doenças crônicas não transmissíveis. No Brasil, a alimentação enquanto um direito social encontra-se em disputa, como todos os outros direitos, em virtude da crise econômica global e sua expressão em nível local. Este ensaio visa a oferecer uma reflexão sobre os contornos que o Direito Humano à Alimentação Adequada (DHAA) vem apresentando no Brasil na história recente. Para tanto, optou-se por oferecer uma análise crítica sobre esses contornos. O artigo se estrutura em três partes: a primeira destaca as desenvolturas do tema a partir da agenda da segurança alimentar e nutricional global e local; a segunda explicita o percurso da construção histórica mais recente no cenário nacional e os desafios atuais mediante ao cenário de desmontes dos direitos sociais; e a terceira lança alguns questionamentos para a tomada de consciência sobre as posições e as ações assumidas pelos agentes sociais envolvidos.

PALAVRAS-CHAVE Segurança alimentar e nutricional. Fome. Política pública. Direitos humanos. Dieta.

1 Universidade de São Paulo (USP) - São Paulo (SP), Brasil.

luciadsguerra@usp.br

2 Universidade Federal de Mato Grosso (UFMT) -

Cuiabá (MT), Brasil.

3 Universidade Federal de São Paulo (Unifesp) - São Paulo (SP), Brasil.

\begin{abstract}
In the contemporary scenario, the triad 'food-health-merchandise' gets 'thick' and 'dilutes' due to the rearrangements of global economic crises and their local expressions in capitalist political-economicsocial dynamics. Reproducing itself in its different faces: that of scarcity - hunger, malnutrition, nutritional deficiencies; and the problems arising from overconsumption of highly industrialized foods - overweight, obesity and chronic non-communicable diseases. In Brazil, food as a social right is in dispute, like all other rights, due to the global economic crisis and its expression at the local level. This essay aims to offer a reflection on the contours that the Human Right to Adequate Food (HRAF) has been presenting in Brazil in recent history. For this purpose, it was decided to offer a critical analysis on these outlines. The article is structured in three parts: the first highlights the development of the theme from the global and local food and nutritional security agenda; the second explains the path of the most recent historical construction on the national scene and the current challenges through the dismantling scenario social rights; and the third raises some questions for raising awareness about the positions and actions taken by the social agents involved.
\end{abstract}

KEYWORDS Food and nutrition security. Hunger. Public policy. Human rights. Diet. 


\section{Introdução}

No âmbito da Segurança Alimentar e Nutricional (SAN), toda pessoa deve ter preservada a garantia do Direito Humano à Alimentação Adequada (DHAA), nos aspectos da suficiência (proteção contra a falta de alimentos e a desnutrição), da qualidade (prevenção de doenças associadas à alimentação) e da adequação (apropriação às circunstâncias sociais, ambientais e culturais) ${ }^{\mathbf{1}, \mathbf{2}}$. Por sua vez, situações de Insegurança Alimentar e Nutricional (IAN) se expressam concretamente através da

fome, obesidade, doenças associadas à alimentação inadequada, consumo de alimentos de qualidade duvidosa ou prejudicial à saúde, estrutura de produção de alimentos predatória em relação ao ambiente, bens essenciais com preços abusivos e imposição de padrões alimentares que não respeitem a diversidade cultural ${ }^{3}$.

A 'alimentação adequada' pode ser entendida como um ato social, cultural e biológico que envolve um conjunto de hábitos e substâncias as quais o homem utiliza, não só com relação às suas funções vitais, mas, também, como um elemento da sua cultura para manter ou melhorar a sua saúde 4 . $\mathrm{O}$ ato de se alimentar é permeado pelos princípios aplicados à nutrição, como variedade, equilíbrio, moderação e prazer (sabor), que envolvem a dimensão sensorial e se relacionam diretamente com a construção mais recente do que vem a ser 'comida de verdade'5,6.

Entre as dimensões que abarcam a alimentação adequada estão o acesso à informação, $o$ acesso a recursos financeiros ou naturais (terra, água), a adequação nutricional, a qualidade sanitária, a diversidade étnico-racial e de gênero, o respeito e a valorização da cultura alimentar nacional e regional, o consumo de alimentos livres de contaminantes, de agrotóxicos e de organismos geneticamente modificados e também a realização de outros direitos, como a saúde, a educação, o trabalho e o lazer.
Acabar com a fome e a miséria consistiu na primeira meta da Organização das Nações Unidas (ONU) para o alcance dos oito Objetivos de Desenvolvimento do Milênio (2000-2015), que visam ao enfrentamento de questões ligadas aos direitos humanos, como a alimentação, o meio ambiente, os direitos das mulheres e os direitos sexuais 8 . Segundo a Food and Agriculture Organization (FAO), no ano de $2011,14,3 \%$ da população mundial (1,02 bilhão de pessoas) estavam em situação de fome, considerada a face mais grave da IAN². Em 2015, houve diminuição do número de pessoas em situação de fome no mundo (795 milhões), mas ainda permanecem populações vulneráveis em Regiões do Oeste da Ásia, África Central, África Subsaariana e alguns países da América Latina ${ }^{10}$.

A ONU definiu o período de 2016 a 2025 como a 'Década de Ação pela Nutrição', com objetivo de reforçar as ações de alimentação e nutrição em escala global, reconhecer a necessidade de erradicar a fome e evitar as diversas formas de nutrição inadequada ${ }^{11}$ para enfrentamentos das situações de IAN. A definição dessa década visa a trazer o tema da alimentação e da nutrição para o centro das discussões nos âmbitos internacional e nacional, dos governos e da sociedade.

Dados do Relatório da FAO, El Estado de La Seguridad Alimentaria y La Nutrición en el Mundo ${ }^{12}$, mostram que cerca de 820 milhões de pessoas não tiveram acesso suficiente a alimentos no ano de 2018 , havendo um aumento consecutivo quando comparado ao ano de 2017, em que eram 811 milhões o número de pessoas nessa situação. Isso representa um enorme desafio para os países alcançarem os Objetivos do Desenvolvimento Sustentável (2015-2030), que contemplam as dimensões econômica, social e ambiental, particularmente, no que diz respeito à Meta 2 - 'fome zero e agricultura sustentável'. Visto que, frente à recessão econômica, a fome tem aumentado em países nos quais o crescimento econômico está paralisado, particularmente aqueles de renda média e 
aqueles que dependem em grande medida do comércio internacional de matérias primas.

Atualmente, países latino-americanos, como o Brasil, experimentam uma transição nutricional marcada pela dupla face de questões ligadas a inadequações na alimentação. Coexistem a desnutrição e as carências nutricionais; o sobrepeso e a obesidade, associados a um conjunto de Doenças Crônicas Não Transmissíveis (DCNT) ${ }^{\mathbf{1 3 - 1 5}}$. Estas, por sua vez, têm sido um sério problema de saúde pública global, responsáveis por $80 \%$ das mortes que ocorrem nos países em desenvolvimento $^{16}$. O cenário das doenças associadas à nutrição (obesidade, hipertensão, diabetes) tem onerado os gastos públicos com saúde, devido ao custo do tratamento para os indivíduos, famílias e, principalmente, para os sistemas de saúde ${ }^{17}$.

No Brasil, a crescente prevalência de sobrepeso e obesidade constitui um dado expressivo dentro do perfil epidemiológico da população brasileira: $54 \%$ da população maior de 18 anos vivenciam essa situação ${ }^{15}$. Isso sinaliza a necessidade de investir e fortalecer a alimentação da população, tomando a saúde, por meio da Atenção Primária à Saúde (APS), como cenário privilegiado para tal prática. Além de ser um espaço privilegiado para o desenvolvimento de ações que possam contribuir para a diminuição das desigualdades em saúde e para a SAN ${ }^{18-20}$, com trabalho articulado e intersetorial de promoção, prevenção, tratamento e recuperação da população. Não há como negar a forte interface entre a saúde e a alimentação, pois ambas compartilham de princípios comuns, e a alimentação é um elemento constitutivo da condição de saúde-doença dos indivíduos, e, como tal, também é socialmente produzida. Assim, a SAN é uma questão central para referenciar a saúde da população e o desenvolvimento de um país²1.

Com base no exposto, este ensaio visa a oferecer uma reflexão sobre os contornos que o DHAA vem apresentando no Brasil na história recente. Para tanto, optou-se por oferecer uma análise crítica sobre esses contornos. $\mathrm{O}$ artigo se estrutura em três partes: a primeira destaca as desenvolturas do tema a partir da agenda da segurança alimentar e nutricional global e local; a segunda explicita o percurso da construção histórica mais recente no cenário nacional e os desafios atuais mediante o cenário de desmontes dos direitos sociais; e a terceira lança alguns questionamentos para a tomada de consciência sobre as posições e as ações assumidas pelos agentes sociais envolvidos.

\section{A alimentação como um direito humano: desenvolturas da Segurança Alimentar e Nutricional do global ao local}

A alimentação, a partir da perspectiva da SAN, passa a ter destaque no período entreguerras. Na I Guerra Mundial (1914-1918), o termo 'segurança alimentar' começou a ser utilizado na Europa relacionado à 'segurança nacional', ou seja, era ligado à capacidade de cada país de produzir seus próprios alimentos para que não ficasse exposto a problemas relacionados a questões políticas ou militares. Na II Guerra Mundial (1939-1945), o termo era entendido como uma questão de disponibilidade de alimentos. A partir de 1950, o mundo passa a vivenciar a crise na produção de alimentos, que impulsionou, nas décadas de 1960 e 1970, a Revolução Verde, cujo objetivo era aumentar a produção associada ao uso de novas variedades genéticas e fortemente dependentes de insumos químicos; tinha como modelo agrícola a monocultura de alimentos, que, posteriormente, trouxe graves consequências ambientais, econômicas e sociais, tais como: redução da biodiversidade, menor resistência a pragas, êxodo rural e contaminação do solo e dos alimentos por agrotóxicos.

A crise mundial de produção de alimentos levou à realização da I Conferência Mundial de Alimentação (1974). Essa conferência teve o propósito de repensar uma política estratégica 
para o armazenamento e a produção de alimentos com o intuito de garantir a regularidade do abastecimento ${ }^{\mathbf{2 2}}$. Nesse período, permaneceu a ideia da alimentação como um fenômeno exclusivamente econômico, relacionado à produção, à distribuição e ao consumo de alimentos, sem considerá-la um fator essencialmente relacionado aos interesses da saúde pública e à dimensão dos direitos humanos.

No final da década de 1980 e início de 1990, havia intensa movimentação internacional para afirmação dos direitos humanos. Em 1993, houve a Conferência Internacional de Direitos Humanos, realizada em Viena, um marco importante que declarou: "todos os direitos humanos fundamentais são universais, indivisíveis, interdependentes e interrelacionados"23(4), conforme disposto no art. $5^{\circ} \mathrm{da}$ declaração da conferência. Esse momento relembrou os governos de todo o mundo do papel fundamental dos Estados na construção do reconhecimento dos direitos humanos no âmbito nacional e das garantias para a sua efetivação, conforme os acordos firmados nos pactos internacionais.

No ano de 1996, em Roma, foi realizada a Cúpula Mundial da Alimentação, um momento de grande importância que contribuiu para repensar a alimentação como um direito humano fundamental. Essa reunião possibilitou firmar o papel essencial da garantia do DHAA para a SAN, e foram incorporadas noções de equidade, justiça e relações éticas entre a geração atual e as futuras, o direito à vida, à dignidade humana, à autonomia e à satisfação de outras necessidades fundamentais ${ }^{2}$.

Um dos encaminhamentos resultantes dessa cúpula foi a definição do conceito e das formas de operacionalização do DHAA, criada a partir de uma interpretação acerca do art. $11^{\circ}$ do Pacto Internacional sobre Direitos Econômicos, Sociais e Culturais (Pidesc) (Comentário Geral $\mathrm{n}^{\circ} 12$ 'O direito humano à alimentação', 1999, parágrafo 2)24(2):

O direito à alimentação adequada realiza-se quando cada homem, mulher e criança, sozinho ou em companhia de outros, tem acesso físico e econômico, ininterruptamente, à alimentação adequada ou aos meios para sua obtenção. 0 direito à alimentação adequada não deverá, portanto, ser interpretado em um sentido estrito ou restritivo, que o equaciona em termos de um pacote mínimo de calorias, proteínas e outros nutrientes específicos. $O$ direito à alimentação adequada terá de ser resolvido de maneira progressiva. No entanto, os Estados têm a obrigação precípua de implementar as ações necessárias para mitigar e aliviar a fome mesmo em épocas de desastres, naturais ou não.

Desse modo, afirma-se que a fome deve ser concebida a partir de diferentes dimensões e ser entendida nas suas faces fortemente subjetivas, que se constroem em um continuum que parte desde a vontade de comer (relacionada às necessidades fisiológicas do corpo biológico), pela situação de nutrição inadequada (causada por desbalanço energético e/ou de nutrientes), chegando às necessidades históricas, culturais, psicológicas e espirituais do ato de alimentar-se, que denotam a incorporação da noção de dignidade humana ${ }^{1,25}$.

É indubitável que a fome, sob uma concepção ampliada, constitui-se em violência ao ser humano e violação ao seu direito à vida. A alimentação é um direito humano fundamental que possui, em sua essência, a discussão do princípio da proteção da 'dignidade da pessoa humana', semelhante aos princípios do direito

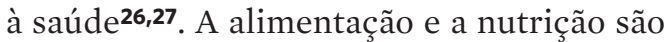
essenciais para a promoção e proteção da vida, pois possibilitam a afirmação do potencial de crescimento e desenvolvimento humano com qualidade de saúde e cidadania ${ }^{28}$.

As situações de IAN possibilitam analisar as relações entre a alimentação e a saúde das populações tanto no âmbito individual como coletivo, porque apresentam determinantes relacionados às condições de vida e ao grau de desenvolvimento humano, social e econômico $^{29,30}$. Alguns estudos permitem caracterizar as pessoas vulneráveis à situação de IAN: são pessoas com cor da pele preta ou parda, 
baixa renda, baixa escolaridade, que experimentam condições de moradia e saneamento precárias e têm sua saúde comprometida ${ }^{31-35}$. Adicionalmente, é possível conjecturar que situações de IAN trazem em si marcas das desigualdades sociais, étnico-raciais e de gênero, da falta de acesso e disponibilidade dos alimentos e do consumo de alimentos de qualidade nutricional inadequada ${ }^{\mathbf{1 0} 36}$.

Nesse sentido, quando há a violação de um direito humano, muito provavelmente há a violação concomitante de outros direitos humanos ${ }^{37}$. Então, compreender que existem pessoas ou populações em situação de IAN significa assumir a violação do DHAA e presumir a de outros direitos humanos fundamentais, como saúde, trabalho, moradia, educação e lazer. Essa vulnerabilidade está pautada na existência de outras vulnerabilidades de relações sociais, fatores contextuais e aspectos individuais que, acompanhados da falta de aparatos governamentais e da sociedade civil, limitam a capacidade de ação das pessoas ${ }^{38,39}$.

O 'Marco Estratégico Global para a SAN' da $\mathrm{FAO}^{40}$ reporta, explicitamente, a importância da integração dos princípios dos direitos humanos para a construção da SAN: a participação, a prestação de contas, a não discriminação, a transparência, a dignidade humana, a delegação de poder e o estado de direito.

No entanto, a efetivação do DHAA colide com a dinâmica capitalista, a qual mercadoriza o alimento e reifica o ato de se alimentar ${ }^{41}$. Nessa relação entre sujeito e alimento, o que importa na dinâmica capitalista é primordialmente a inserção do sujeito no mundo do consumo. Ela se utiliza do alimento industrializado para apelar à dimensão fetichizada do ato de consumir, reduzindo a nutrição ao limiar de sobrevivência, quando esta ainda é possível. A transformação do alimento em mercadoria perpassa o aumento da tecnologia na produção, como expressão do incremento do capital constante (máquinas) em relação ao capital variável (força de trabalho). Essa dominância tecnológica se maximiza na vida concreta dos sujeitos pela oferta de alimentos altamente industrializados, de baixo valor nutricional, alta densidade calórica, ricos em substâncias que os tornam agradáveis/palatáveis ao gosto e capturam os desejos individuais e coletivos, por meio de uma 'palatabilidade estéril' que ocorre via quatro ingredientes principais: açúcar, sal, gordura ${ }^{\mathbf{4 2}}$, e aditivos alimentares.

Nesse contexto, o ato de se alimentar é apenas mais um ato mecânico do cotidiano, desconfigurado pelo consumo acelerado do alimento-mercadoria ${ }^{42}$ e pelo esvaziamento do sentido de comensalidade, outrora constitutivo da alimentação ${ }^{\mathbf{3}}$. Hoje, alimentar-se é uma ação instrumental, reificada e submissa ao processo de individualização vigente. A ordem instituída, supostamente defensora da liberdade individual, realiza justamente o seu contrário: a aquisição instantânea de quaisquer produtos prontos ou quase prontos para consumo.

No mundo globalizado, a indústria de alimentos e a rede de distribuição/comercialização, tal como vêm se organizando desde o século XX e a sua intensificação no século XXI, representam ameaças à soberania alimentar dos países, tornando necessária, cada vez mais, a luta por sistemas agroalimentares sustentáveis. A concentração do mercado de produção de sementes e o comércio de agrotóxicos têm impactado substancialmente o que se planta, se cria e se come, e, claro, seria impossível crer que não houve implicações na qualidade dos alimentos. A primeira implicação é que os sistemas agroalimentares são atingidos por uma lógica global de captura e homogenização das diversidades alimentares presentes em cada cultura ${ }^{42}$.

É pertinente lembrar que a noção de soberania alimentar vem sendo construída e difundida pelos movimentos sociais desde meados da década de 1990, com a principal motivação de responder à perda de capacidade dos Estados Nacionais de formularem suas políticas agrícolas e alimentares no contexto da progressiva internacionalização da economia, comandada pela supremacia e pelo avanço do agribusiness. Por sua vez, torna-se importante 
fazermos o contraponto a essa dinâmica global e local, definindo a soberania alimentar como:

o direito dos povos definirem suas próprias políticas e estratégias sustentáveis de produção, distribuição e consumo de alimentos que garantam o direito à alimentação para toda a população, com base na pequena e média produção, respeitando suas próprias culturas e a diversidade dos modos camponeses, pesqueiros e indígenas de produção agropecuária, de comercialização e gestão dos espaços rurais, nos quais a mulher desempenha um papel fundamental [...]. A soberania alimentar é a via para erradicar a fome e a desnutrição e garantir a segurança duradoura e sustentável para todos os povos44(4-5).

Essa tensão entre o global e o local, nesse mundo globalizado, parece ser uma distopia para a concretização dos direitos humanos, como a alimentação, pois as decisões produzidas no âmbito internacional tendem a estar pautadas no consenso entre países, sem compreender a existência de diferenças culturais que estão postas para a implementação de acordos e construção de políticas públicas no âmbito local. Nesse sentido, permanece a difícil tarefa de associar o dinamismo econômico, a promoção de justiça social, a melhoria sustentável da qualidade de vida, do ambiente, na tentativa de firmar a soberania alimentar e a lógica de justiça social.

\section{A construção histórica do DHAA no Brasil e os desafios atuais mediante o cenário de desmontes dos direitos sociais}

\footnotetext{
Para essa construção histórica, será necessário recorrer brevemente ao período de 1930 a 1986, para tentar entender as bases conceituais e políticas da construção desse direito a partir da trajetória da SAN, já devidamente descrita na literatura ${ }^{1,45,46}$.
}

Desde a década de 1930, o diagnóstico da fome, mapeado por Josué de Castro, denunciou que os problemas alimentares presentes na população brasileira consistem em um complexo simultâneo de manifestações biológicas, econômicas e sociais, mediado por fatores políticos, seja pela omissão do Estado ou da própria sociedade em consentir com tal situação ${ }^{47}$.

Os primeiros programas governamentais de alimentação e nutrição são das décadas de 1930 e 1940 e foram impulsionados pelo Plano Salte - Saúde, Alimentação, Transporte e Energia. Esse período foi marcado pelo intenso processo de urbanização e industrialização, em que os problemas alimentares brasileiros já denunciavam a forte relação entre a alimentação, a miséria, a pobreza e o atraso econômico. Esses programas se estenderam até o início da década de 1960 e estavam focalizados em grupos específicos, como trabalhadores, gestantes, crianças e escolares. Continham uma abordagem voltada à distribuição de gêneros alimentícios, como o leite em pó, associados à padronização de práticas e hábitos alimentares que reforçam a relação do alimento como mercadoria, já que estava sujeita aos interesses econômicos internacionais do escoamento de excesso de produção ${ }^{46}$.

Durante a ditadura militar, as questões ligadas à alimentação eram coordenadas pelo Instituto Nacional de Alimentação e Nutrição (Inan) e centralizavam-se em programas voltados para a produção e comercialização de alimentos e, posteriormente, suplementação das carências nutricionais, mais uma vez, voltadas aos grupos prioritários. No entanto, nesse período, destacam-se a criação de alguns mecanismos institucionais que podem ser identificados como iniciativas de articulação intersetorial no âmbito da SAN, como as ações do II Programa Nacional de Alimentação e Nutrição (Pronan) ${ }^{45}$.

Guardado o devido 'salto histórico', mais recentemente, a SAN ganha maior visibilidade no cenário nacional enquanto movimento político-normativo para a efetivação do DHAA. Em 1985, é feita a primeira referência 
a uma proposta de política pública: 'Segurança Alimentar - proposta de uma política contra a fome'. Apesar de suas poucas consequências práticas, a proposta continha as bases das diretrizes de uma política nacional de SAN e a criação de um Conselho Nacional de SAN, o Consea'.

Em 1986, houve uma intensa movimentação na área da saúde pública com a luta pela garantia do direito à saúde no Brasil (o Movimento da Reforma Sanitária), e, nesse momento, a SAN esteve presente entre o quadro de temas das emendas apresentadas ao anteprojeto da Constituinte ${ }^{\mathbf{4 8}}$. Nesse mesmo período, destaca-se a realização da I Conferência Nacional de Alimentação e Nutrição no interior da VIII Conferência Nacional de Saúde ${ }^{\mathbf{9}}$, onde foi lançada a noção inicial de SAN, que acrescentou ao termo consagrado internacionalmente 'segurança alimentar' o adjetivo 'nutricional', com o objetivo de interligar os dois principais enfoques que estiveram na base da sua construção, o socioeconômico e o de saúde e nutrição. Em adição, houve a proposta de um Conselho Nacional de Alimentação e Nutrição que formulasse uma política nacional para a área e a criação de um Sistema Nacional de SAN integrado por conselhos e sistemas nas esferas estadual e municipal1.

No âmbito do governo federal, a década de 1990 foi marcada pelo discurso da estabilização econômica, da 'modernização' do Estado, com a redução dos recursos financeiros, o esvaziamento e a extinção de programas e iniciativas de alimentação e nutrição junto ao Estado, relegando a SAN a segundo plano ${ }^{46,50}$. No entanto, houve importantes mobilizações sociais que buscavam contestar essas ações.

Em 1993, por exemplo, o 'Movimento pela Ética na Política' liderado por Herbert José de Souza, o 'Betinho', que impulsionou o processo de formação de Comitês de Combate à Fome e ganhou força com o movimento social 'Ação da Cidadania contra a Fome, a Miséria e Pela Vida'. Os comitês tinham abrangência local, municipal e estadual, eram constituídos por setores diversos da sociedade e tinham a articulação de dois tipos de ações: emergenciais e de pressão de opinião pública ${ }^{45}$. O movimento resultou na criação da Organização Não Governamental (ONG) 'Ação da Cidadania contra a Fome, a Miséria e Pela Vida', ainda existente nos dias atuais.

Naquele mesmo ano, houve a criação do Consea (Decreto ${ }^{\circ}$ 807, de 22 de abril de 1993), e iniciou-se a construção de uma agenda nacional de SAN, que deu origem às iniciativas de descentralização de programas de alimentação e nutrição: alimentação escolar, ampliação do Programa de Alimentação do Trabalhador (PAT) e distribuição de estoques públicos de alimentos às populações carentes'. Com o Consea, deu-se início a organização e realização de conferências nacionais de SAN, espaços importantes para a construção do DHAA no Brasil. Em 1994, houve a I Conferência de SAN, que elaborou o primeiro esboço da definição atual de SAN, e foram produzidos, também, uma declaração política e um documento programático para a criação de uma Política Nacional de SAN ${ }^{35}$.

O Consea durou pouco tempo, sendo extinto em 1995 pelo governo Fernando Henrique Cardoso. Essa interrupção prejudicou a revisão e o aprofundamento da SAN no cenário brasileiro, principalmente no que se refere à participação da sociedade civil na construção de políticas públicas para a garantia do DHAA ${ }^{1}$. A proposta apresentada na época foi o 'Programa Comunidade Solidária', que contou com um conselho para avançar na 'parceria' Estadosociedade. Essa estratégia pretendia enfrentar o combate à fome, à pobreza e à exclusão social inspirado nas experiências de mobilização da sociedade civil, no entanto, dentro de um plano focalizado no discurso neoliberal, de flexibilidade e parcerias entre o Estado mínimo, o mercado e o terceiro setor ${ }^{36,46}$.

Houve a intenção do governo FHC de dar continuidade aos trabalhos do Consea, com a criação de um Comitê Setorial de SAN. No entanto, a ideia de incorporação da SAN, como um objetivo estratégico orientador de políticas públicas, submergiu as prioridades gerais do governo, limitando-se ao desenvolvimento de 
programas focalizados no lugar da construção de uma política pública ${ }^{1}$. Nesse cenário, a exceção foi alcançada pela Política Nacional de Alimentação e Nutrição (PNAN) (Portaria n ${ }^{\circ}$ 710, de 10 de junho de 1999, do Ministério da Saúde), cujo objetivo era estabelecer diretrizes específicas para as ações de alimentação e nutrição dentro do setor saúde ${ }^{46}$.

Em 1998, a sociedade civil brasileira se organizou para a criação do Fórum Brasileiro de SAN (FBSAN), que congregou entidades distribuídas por todas as regiões do País. O FBSAN, desde a sua existência, tem contribuído para a mobilização social e o avanço nas formulações sobre SAN, organizando a participação brasileira em fóruns internacionais e direcionando a atuação no âmbito local36.

Houve retrocessos na apropriação da noção de SAN como garantia do DHAA no âmbito do governo federal, no entanto, ocorria a sua ampliação em duas portas nas esferas estadual e municipal da administração pública: 0 abastecimento alimentar ligado à produção e às práticas alimentares, e a área de assistência/ desenvolvimento social1.

Chega-se, assim, a um marco importante da agenda pública da SAN para a garantia do DHAA, o 'Projeto Fome Zero: uma Política Nacional de SAN para o Brasil', lançado em 2001 pelo Instituto Cidadania, que, posteriormente, foi a base do Programa Fome Zero, apresentado em 2003 pelo governo federal. A criação desse programa possibilitou a inserção do discurso do pacto social de combate à fome e à miséria, da pauta do direito à alimentação e da SAN, como prioridade do governo federal brasileiro através da construção de políticas intersetoriais desenvolvidas em três modalidades de intervenção: estruturais, específicas e locais ${ }^{\mathbf{4 3}}$.

Para isso, foi montado um arcabouço operacional que envolveu diversos ministérios, a criação de um Ministério Extraordinário de Segurança Alimentar e Combate à Fome (Mesa), além da reativação do Consea. Após muitas críticas, o Mesa foi reformulado, criando-se o Ministério do Desenvolvimento Social e Combate à Fome (MDS) ${ }^{50}$, existente até o ano de 2016, após o golpe institucional, transformando-se, no governo Temer, em Ministério do Desenvolvimento Social e Agrário (MDSA). Em 2019, foi extinto pelo governo Bolsonaro, através da Medida Provisória ${ }^{\circ} 870$, e incorporado ao Ministério da Cidadania.

Entre as ações e os programas desenvolvidos por esse Ministério, destaca-se a criação do Programa Bolsa Família (PBF), em 2004, que unificou outros programas de transferência de renda originários do governo $\mathrm{FHC}^{50}$. Segundo o MDSA, o PBF beneficiou, em 2015, cerca de 13,9 milhões de famílias, e estudos mostram o seu impacto positivo na aquisição e qualidade dos alimentos nos domicílios e na alimentação e no crescimento infantil $51,52$.

Em 2011, houve a continuidade na construção da agenda pública de SAN junto ao governo federal, com o plano de governo 'Brasil sem Miséria', criado para superar a extrema pobreza no País. O plano foi organizado em três eixos: a garantia de renda, para alívio imediato da situação de pobreza; o acesso a serviços públicos, para melhorar as condições de educação, saúde e cidadania das famílias; e a inclusão produtiva, para aumentar as capacidades e as oportunidades de trabalho e geração de renda entre as famílias mais pobres do campo e da cidade. Por conseguinte, foi lançado o 'Brasil Carinhoso', após o plano anterior ter identificado que a miséria tinha maior incidência entre crianças de 0 a 6 anos e adolescentes de até 15 anos. Este segundo plano foi concebido numa perspectiva de atenção integral e envolveu três importantes aspectos ligados ao desenvolvimento infantil: renda, educação e saúde. No entanto, principalmente a partir de 2014, o País é marcado pelo declínio do crescimento econômico. As conquistas dos anos anteriores, baseadas na inclusão pelo consumo e altamente dependentes do mercado externo, pareceram ser efêmeras. Segue-se uma crise política, marcada pelo distanciamento entre o governo e sua base social ${ }^{53}$.

Em 2016, o Brasil passa por um processo de golpe institucional de Estado e deslegitimação da democracia, enquanto procedimento. Em 
que pesem os diversos motivos que geraram a crise política do País (que não são objetivos deste texto, mas que influenciam no tema abordado), o fato é que as políticas públicas estruturantes, como alimentação, saúde, educação e assistência social, deixaram de ser prioridades, iniciando-se o desmonte realizado pelo governo ilegítimo. Ficando em segundo plano e associadas a medidas de ajustes fiscais, definidas por cortes e redução de gastos públicos, bem como reformas institucionais reducionistas, levando a retrocessos concretos de conquistas sociais e ameaça real à soberania alimentar. Tais ajustes fiscais, considerados um modelo de contingenciamento preventivo são concretamente uma "rota abstrata de contingenciamento que nega a plena eficácia dos direitos fundamentais"54(1101).

O plano de governo 'A Travessia Social: uma ponte para o futuro', lançado posteriormente ao golpe, é um exemplo de projeto neoliberal que propõe uma reorganização do País para supostamente conter a crise econômica e retomar o crescimento, aos moldes da implantação de um Estado Mínimo. As medidas para a concretização dessa proposta estão ligadas ao controle dos gastos públicos, destacando-se a Proposta de Emenda à Constituição ${ }^{0} 55$, de 2016 - 'PEC do Teto dos gastos públicos' (PEC 55) -, que instituiu o Novo Regime Fiscal no âmbito dos Orçamentos Fiscal e da Seguridade Social da União com o intuito de 'congelar' as finanças do Estado por 20 anos (atual Emenda Constitucional-95). Medida que tramitou de forma apressada nas instâncias legislativas do Estado brasileiro e com limitada participação da sociedade, embora apresentada para consulta pública no canal e-Cidadania do Senado Federal, com resultado final de 23.770 a favor e 345.718 contra. Assistiu-se à opinião popular ser claramente ignorada, visto que a PEC 55 foi aprovada no Legislativo e promulgada como Emenda Constitucional no 95, em 15 de dezembro de 2016 ( $\mathrm{EC} \mathrm{n}^{\circ}$ 95).

Nesse sentido, políticas e programas que visam à garantia dos direitos sociais estão comprometidas, se adicionarem-se à EC $\mathrm{n}^{0} 95$ as propostas atuais já aprovadas no Estado brasileiro (a reforma trabalhista e da previdência social). Esse cenário de desmonte dos direitos sociais já vem gerando impactos negativos diretos no desenvolvimento humano e social do País, anunciando o descrédito do Brasil perante organizações internacionais. Cenário este agravado com a pandemia da Covid-19.

Ratifica-se que, em um contexto de economia liberal, os programas de governo ficam ajustados às variações de mercado, restringindo as possibilidades de obterem-se resultados positivos nos campos social, político e dos direitos humanos ${ }^{55}$.

Tendo em vista que o Brasil foi o primeiro país em desenvolvimento a colocar a fome e a pobreza no centro das políticas públicas, isso contribuiu para que o País saísse do Mapa da Fome da ONU, no ano de 2014. As estratégias e ações adotadas para atingir esse patamar tiveram escopo intersetorial visando à garantia do DHAA, com investimento em transferência de renda, merenda escolar, agricultura familiar e apoio à captação de água para consumo humano e produção de alimentos em regiões de seca ${ }^{56}$.

Dados do Instituto de Pesquisas Econômicas Aplicadas (Ipea), do Ministério do Planejamento, Desenvolvimento e Gestão Brasileiro (2016), mostram que a $\mathrm{EC}^{\circ} 95$ deve gerar em 20 anos a perda de até $\mathrm{R} \$ 743$ bilhões para o financiamento do SUS e para a garantia do direito à saúde de grupos sociais mais vulneráveis. As reconfigurações do subfinanciamento da saúde pública possibilitam projetar um futuro de condições ainda piores para a preservação da vida ${ }^{57}$, da dignidade humana, do avanço permanente da inovação tecnológica no setor saúde e do aumento das DCNT. Além de perdas equivalentes a até R \$ 868 bilhões na Política de Assistência Social, que impactarão diretamente programas sociais como o Programa Bolsa Família, o Benefício de Prestação Continuada, o Sistema Único de Assistência Social (Suas) e o Sistema Nacional de Segurança Alimentar e Nutricional (Sisan) ${ }^{\mathbf{5 8}}$.

Como diversas políticas sociais são operacionalizadas pelos estados e municípios em regime de cofinanciamento, as reduções nos gastos públicos federais podem representar a 
paralisação de alguns serviços locais e a descontinuidade de políticas sociais nos âmbitos estadual e municipal. À medida que o Sisan, o Suas e o SUS sejam enfraquecidos continuamente, a sociedade terá reduzida sua capacidade de monitoramento do cumprimento das obrigações do Estado, como a de garantir o DHAA e a saúde. Isso já se comprovou com a extinção do Consea (em 2019, pelo governo Bolsonaro, por meio da $\mathrm{MP}^{\mathrm{o}}$ 870) - órgão importante para a sociedade civil (que ocupava dois terços da sua representação) e de assessoramento imediato da Presidência da República. Algumas de suas funções eram articular, acompanhar e monitorar as ações inerentes à Política Nacional de SAN e ao Plano Nacional de SAN, além de zelar pela efetividade do $\mathrm{DHAA}^{5}$.

Considerando os avanços, sem deixar de lado o construto histórico da complexa realidade alimentar brasileira e suas profundas marcas de desigualdades sociais ${ }^{59,60}$, o cenário atual do Brasil aponta para a desconstrução das políticas públicas sociais e anuncia processos de instabilidade na garantia dos direitos sociais, como, por exemplo, o DHAA; que foram agravados pela pandemia da Covid-19.

O DHAA e os demais direitos sociais estão em disputa a todo tempo, seja no plano teórico-conceitual, na construção ou permanência de valores ou também no âmbito da formulação e implementação das políticas públicas, à medida que a organização social e política e as relações de poder se rearranjam em uma sociedade, constituindo-se num campo em construção61.

\section{Afinal, estamos 'espessando' ou 'diluindo' o Direito Humano à Alimentação Adequada no Brasil?}

Na discussão para a realização do DHAA no âmbito global e local, a ONU definiu a Década da Ação pela Nutrição (2016-2025), que traz para o centro da sociedade, dos governos e das universidades a oportunidade de debater o tema da alimentação e nutrição, possibilitando a construção de estratégias para o fortalecimento de políticas públicas que confiram materialidade para o DHAA.

No contexto da implementação local das políticas públicas para efetivação do DHAA, destaca-se o caráter relevante e central da inclusão dos recursos humanos, os profissionais de saúde, como participantes das políticas em seus aspectos político, administrativo, técnico e social. Atrelada a isso, há a necessidade de que sejam revistas as estratégias para disseminação da noção de alimentação adequada (constitutiva do valor da alimentação), que se tem tentado construir nas políticas públicas e nos marcos de referências que orientam os serviços, os profissionais de saúde e a população a respeito do tema, uma vez que elas parecem não alcançar todos esses agentes de efetivação do DHAA a ponto de se tornarem corresponsáveis na sua práxis cotidiana.

Em tempos de crise política, econômica, social, sanitária, a garantia dos direitos sociais, como alimentação, saúde, educação, trabalho e moradia, é tradicionalmente impactada pela opção dos governos da ocasião de subsumir o papel do Estado frente às dinâmicas neoliberais. Para o cenário brasileiro, a ideia de um Estado em crise financeira, que deve gastar pouco com suas políticas públicas sociais, parece convencer um povo que, na verdade, necessita da efetivação de seus direitos humanos fundamentais.

O discurso da estabilização econômica tem se mostrado capaz de sobrepujar as agendas de desenvolvimento humano no País, e as discussões mais necessárias estão veladas, como, por exemplo, quais as consequências da política atual para a garantia dos direitos sociais? Quem são os mais afetados? E se esse é o modelo de sociedade que nós, brasileiros, queremos.

A coexistência da fome, da desnutrição, das carências nutricionais junto ao sobrepeso e à obesidade não é apenas uma constatação da epidemiologia nutricional infundida em 
documentos/relatórios de instituições internacionais e nas políticas públicas brasileiras de alimentação que buscam validar a IAN como consequência da superpopulação, da escassez de alimentos, da determinação geográfica e de catástrofes naturais. Trata-se de uma expressão concreta da lógica capitalista e de sua reprodução de desigualdades e pobreza, que tem como um dos seus instrumentos: a alimentação como mercadoria.

Se o capitalismo utiliza a alimentação para reproduzir-se enquanto produto/mercadoria e não como 'alimentação adequada' para todos, não medirá esforços para o emprego de tecnologia na contraversão de uma 'poção mágica' (sal, gordura e açúcar) para a conquista de uma 'palatabilidade estéril' dos alimentos. Se esse é o caminho, não há dúvida de que ele já foi trilhado. Se o atrativo para atender aos desejos dos consumidores se reforça pelo convencimento de uma publicidade enganosa de alimentos, o capitalismo já está empenhado nessa tarefa.

Cabe a reflexão: onde estamos no embate da construção da alimentação que queremos? 'Espessamos' a alimentação como um direito humano fundamental para adensar outros direitos sociais, como a saúde, e a perscrutamos com a lógica de bem humano? Ou ela já se 'diluiu' ordinariamente nesse Estado capitalista e mais ainda entre o cotidiano de trabalhadores: pesquisadores, profissionais de saúde, agentes públicos?

\section{Agradecimentos}

Ao Programa de Pós-Graduação em Nutrição em Saúde Pública da Faculdade de Saúde Pública da Universidade de São Paulo, no qual foi defendida a tese de doutorado que originou este artigo (intitulada 'Direito Humano à Alimentação Adequada e atuação profissional em saúde pública', no ano de 2017). Ao Centro de Estudos e Pesquisas em Direito Sanitário Cepedisa, da Faculdade de Saúde Pública da Universidade de São Paulo.

\section{Colaboradores}

Guerra LDS (0000-0003-0093-2687)* trabalhou na concepção, redação e revisão do manuscrito. Bezerra ACD (0000-0001-91324390)* colaborou para a redação e a revisão crítica do manuscrito. Carnut L (0000-00016415-6977)* colaborou para a redação e a revisão crítica do manuscrito. 


\section{Referências}

1. Maluf RS. Segurança Alimentar e Nutricional. 2. ed. Petrópolis, Rio de Janeiro: Vozes; 2009.

2. Valente FLS. Direito Humano à alimentação: desafios e conquistas. São Paulo: Cortez; 2002.

3. Brasil. Lei Orgânica de Segurança Alimentar e Nutricional, $\mathrm{n}^{\circ} 11.346$, de 15 de setembro de 2006. Cria o Sistema Nacional de Segurança Alimentar e Nutricional - SISAN com vistas em assegurar o direito humano à alimentação adequada e dá outras providências. Diário Oficial da União. 18 Set 2006. [acesso em 2021 fev 10]. Disponível em: http://www.planalto.gov. br/ccivil_03/_ato2004-2006/2006/lei/111346.htm.

4. Canesqui AM, Diez-Garcia RW. Antropologia e nutrição: um diálogo possível. Rio de Janeiro: Fiocruz; 2005.

5. Conselho Nacional de Segurança Alimentar e Nutricional. Relatório Final III Conferência Nacional de SAN: por um desenvolvimento sustentável com soberania e segurança alimentar e nutricional. Fortaleza: Consea; 2007.

6. Conselho Nacional de Segurança Alimentar e Nutricional. Relatório Final $5^{\text {a }}$ Conferência Nacional de SAN - Comida de verdade no campo e na cidade: por direitos e soberania alimentar. Brasília, DF: Conselho Nacional de Segurança Alimentar e Nutricional; 2015.

7. Brasil. Ministério da Saúde, Secretaria de Atenção à Saúde, Departamento de Atenção Básica à Saúde. Dialogando sobre o Direito Humano à Alimentação Adequada no contexto do SUS. Brasília, DF; 2010. (Série F - Comunicação e Educação em Saúde).

8. Organização das Nações Unidas. The Sustainable Development Goals Report. New York: ONU; 2016.

9. Food and Agriculture Organization of the United Nations. El estado de la inseguridade alimentaria en el mundo: como afecta la volatilidade de los precios in- ternacionales a las economias nacionales y la seguridade alimentaria? Roma: FAO; 2011.

10. Food and Agriculture Organization of the United Nations. El estado de la inseguridade alimentaria en el mundo. Cumplimiento de los objetivos internacionales para 2015 em relación el hambre: balance de los desiguales progresos. Roma: FAO; 2015.

11. Organização das Nações Unidas no Brasil. Assembléia geral da ONU proclama Década de Ação sobre Nutrição (2016-2025) [internet]. Geneva: ONUBR; 2016. [acesso em 2016 abr 12]. Disponível em: https://nacoesunidas.org/assembleia-geral-da-onu-proclama-decada-de-acao-sobre-nutricao-2016-2025/.

12. Food and Agriculture Organization of the United Nations. El estado de la inseguridade alimentaria y la nutrición en el mundo 2019. Protegerse frente a la desaceleración y el debilitamiento de la economía. Roma: FAO; 2019.

13. World Health Organization. Report of the commission on ending childhood obesity. Geneva: WHO; 2016.

14. Organização Pan-Americana da Saúde. Modelo de Perl Nutricional da Organização Pan-Americana da Saúde. Washington: Opas; 2016.

15. Schmidt MI, Duncan BB, Silva GA, et al. Doenças crônicas não transmissíveis no Brasil: carga e desafios atuais. Lancet. 2011; (4):61-74.

16. World Health Organization. Global Status Report on noncommunicable diseases 2014: "Attaining the nine global noncommunicable diseases targets; a shared responsibility" [internet]. Geneva: WHO; 2014. [acesso em 2016 jul 28]. Disponível em: http://apps.who.int/iris/bitstream/10665/148114/1/9789241564854_eng.pdf.

17. Abegunde DO, Mathers CD, Adam T, et al. The burden and costs of chronic diseases in low-income and middle-income countries. Lancet. 2007; 370(9603):1929-38. 
18. Rigon SA, Schmidt ST, Bógus CM. Desafios da nutrição no Sistema Único de Saúde para construção da interface entre a saúde e a segurança alimentar e nutricional. Cad. Saúde Pública. 2016; (32):1-10.

19. Cervato-Mancuso AM, Tonacio LV, Silva ER, et al. A atuação do nutricionista na Atenção Básica À Saúde em um grande centro urbano. Ciênc. Saúde Colet. 2012; 17(12):3289-3300.

20. Jaime PC, Silva ACF, Lima AMC, Bortolini GA. Ações de alimentação e nutrição na atenção básica: a experiência de organização no Governo Brasileiro. Rev. Nutr. 2011; 24(6):809-824.

21. Chilton M, Rose D. A rights-based approach to food insecurity in the United States. Am J Public Health 2009; (99):1203-1211.

22. Ação Brasileira pela Nutrição e Direitos Humanos. O Direito Humano à Alimentação Adequada e o Sistema Nacional de Segurança Alimentar e Nutricional. Brasília, DF: ABRANDH; 2013.

23. Declaração e Programa de Ação de Viena: Conferência Mundial sobre Direitos Humanos [internet]. Viena; 1993. [acesso em 2020 jun 1]. Disponível em: https://www.oas.org/dil/port/1993\%20 Declara\%C3\%A7\%C3\%A30\%20e\%20Programa\%20 de\%20Ac\%C3\%A7\%C3\%A3o\%20adoptado\%20 pela\%20Confer\%C3\%AAncia\%20Mundial\%20 de\%20Viena\%20sobre\%20Direitos\%20Humanos\%20 em\%20junho\%20de\%201993.pdf.

24. Organização das Nações Unidas. Comentário Geral $n^{\circ}$ 12: O direito humano à alimentação (art. 11). Comitê de Direitos Econômicos, Sociais e Culturais do Alto Comissariado de Direitos Humanos [internet]. Nova York: ONU; 1999. [acesso em 2016 out 28]. Disponível em: http://www.sesc.com.br/mesabrasil/doc/Direito\%20humano\%20\%C3\%A0\%20 Alimenta\%C3\%A7\%C3\%A3o-Seguran\%C3\%A7a-alimentar.pdf.

25. Valente FLS. Fome, desnutrição e cidadania: inclusão social e direitos humanos. Saúde Soc. 2003; 12(1):5160 .
26. Albuquerque MFM. A segurança alimentar e nutricional e o uso da abordagem de direitos humanos no desenho das políticas públicas para combater a fome e a pobreza. Rev. Nutr. 2009; (22):895-903.

27. Aith FMA. Curso de Direito Sanitário: a proteção do direito à saúde no Brasil. São Paulo: Quartier Latin; 2007.

28. Arruda IKG, Arruda BKG. Nutrição e Desenvolvimento. Cad. Saúde Pública 1994; (10):392-397.

29. Kepple AW, Segall-Corrêa AM. Conceituando e medindo segurança alimentar e nutricional. Ciênc. Saúde Colet. 2011; 16(1):187-199.

30. Buss MP, Pellegrini-Filho A. A Saúde e seus Determinantes Sociais. Physis Rev. Saúde Coletiva. 2007; 17(171):77-9377.

31. Santin GC, Pintarelli TP, Fraiz FC, et al. Associação entre cárie dentária não tratada e insegurança alimentar em escolares. Ciênc. Saúde Colet. 2016; 21(2):573584.

32. McCoy SI, Buzdugan R, Mushavi A, et al. Food insecurity is a barrier to prevention of mother-to-child HIV transmission services in Zimbabwe: a cross-sectional study. BMC Public Health. 2015; (15):3-9.

33. Guerra LDS, Espinosa MM, Bezerra ACD, et al. Insegurança alimentar em domicílios com adolescentes da Amazônia Legal Brasileira: prevalência e fatores associados. Cad. Saúde Pública 2013; 29(2):335-348.

34. Huang J, Oshima KMM, Kim Yi. Does food insecurity affect parental characteristics and child behavior? Testing mediation effects. The Social service review 2010; 84(3):381-401.

35. Kaiser LL, Melgar-Quiñonez HR, Townsend MS, et al. Food insecurity and food supplies in Latino households with young children. J Nutr Educ Behav 2003; (35):148-153.

36. Rocha C, Burlandy L, Magalhães R. Segurança Alimentar e Nutricional: perspectivas, aprendizados e 
desafios para as políticas públicas. Rio de Janeiro: Fiocruz; 2013. p. 171-185.

37. Gruskin S, Mills EJ, Tarantola D. Health and Human Rights 1 History, principles, and practice of health and human rights. Lancet. 2007; (370):449-455.

38. Ayres JRCM, Paiva V, França-Jr I. Conceitos e práticas de prevenção: da História Natural da Doença ao quadro da Vulnerabilidade e Direitos Humanos. In: Paiva V, Ayres JR, Buchalla CM, organizadores. Vulnerabilidade e Direitos Humanos: prevenção e promoção da saúde - Livro I: Da doença à cidadania. Curitiba: Juruá; 2012. p. 71-94.

39. Serapioni M. Os desafios da participação e da cidadania nos sistemas de saúde. Ciênc. Saúde Colet. 2014; 19(12):4829-4839.

40. Food and Agriculture Organization of the United. O Direito Humano à Alimentação Adequada no Marco Estratégico Global para a Segurança Alimentar e Nutricional: consenso global. [direito humano à alimentação adequada: consenso global]. Roma: FAO; 2014.

41. Machado PP, Oliveira NRF, Mendes AN. O indigesto sistema do alimento mercadoria. Saúde Soc. 2016; 25(2):505-515.

42. Esteve EV. O negócio da comida: quem controla nossa alimentação. São Paulo: Expressão popular; 2017.

43. Lima RS, Ferreira Neto JÁ, Farias RCP. Alimentação, comida e cultura: o exercício da comensalidade. Demetra. 2015; 10(3);507-522.

44. Declaração soberania Declaración final del foro mundial sobre soberanía alimentaria: Por el derecho de los pueblos a producir, a alimentarse y a ejercer su soberanía alimentaria [internet]. Havana: Cuba; 2001. [acesso em 2020 jun 1]. Disponível em: https://base. socioeco.org/docs/doc-792_es.pdf.

45. Burlandy L. A construção da política de segurança alimentar e nutricional no Brasil: estratégias e desafios para a promoção da intersetorialidade no âm- bito federal de governo. Cienc. Saúde Colet. 2009; 14(3):851-860.

46. Vasconcelos FAG. Combate à fome no Brasil: Uma análise histórica de Vargas a Lula. Rev Nutr. 2005; 18(4):439-457.

47. Castro J. Geografia da Fome. 8. ed. Rio de Janeiro: Civilização Brasileira; 2008

48. Coelho ETSP. O perfil sanitarista do Parlamento brasileiro: caminhos, interesse e conquistas da saúde nas Assembleias Nacionais Constituintes de 1946 e 198788 [dissertação]. São Paulo: Faculdade de Saúde Pública, Universidade de São Paulo; 2019.

49. Arruda BKG, Arruda IKG. Marcos referenciais da trajetória das políticas de alimentação e nutrição no Brasil. Rev. Bras. Saúde Matern. Infant. 2007; 7(3):319326.

50. Machado M, Rocha DF, Campos MM. Dos movimentos sociais à implementação do Programa Fome Zero (1993-2013): a trajetória da cidadania alimentar no Brasil (20 anos da ação da cidadania e 10 anos do Programa Fome Zero). Seg. Aliment. e Nutr. 2015; 22(2):692-705.

51. Martins APB, Monteiro CA. Impact of the Bolsa Familia program on food availability of low-income Brazilian families: a quasi experimental study. BMC Public Health. 2016; 16(1):827.

52. Segura-Pérez S, Grajeda R, Pérez-Escamilla R. Conditional cash transfer programs and the health and nutrition of Latin American children. Rev. Panam. Salud Publica. 2016; 40(2):124-137.

53. Singer A. A (falta de) base política para o ensaio desenvolvimentista. In: Singer A, Loureiro I. As contradições do Lulismo: a que ponto chegamos? São Paulo: Boitempo; 2016. p. 21-54.

54. Pinto EG. Novo regime fiscal e a constitucionalização do contingenciamento das despesas primárias obrigatórias. Physis Rev de Saúde Coletiva. 2016; 26(4):1097-1101. 
55. Freitas MC, Penna PGL. Segurança Alimentar e Nutricional: a produção do conhecimento com ênfase nos aspectos da cultura. Rev. Nutr. 2007; 20(1):69-81.

56. Food and Agriculture Organization of the United Nations. O Estado da SAN no Brasil: um retrato multidimensional. Relatório 2014. Brasília, DF: FAO; 2014.

57. Mendes A, Carnut L. Capital, Estado, crise e a saúde pública brasileira: golpe e desfinanciamento. Ser Social: Est. Democ. Saúde. 2020; 22(46):9-32.

58. Instituto de Pesquisas Econômicas Aplicadas. Paiva AB, Mesquita ACS, Jaccoud L, Passos L. O novo regime fiscal e suas implicações para a política de assistência social no Brasil. Brasília, DF: IPEA; 2016. (Nota Técnica $n^{\circ} 27$ ).
59. Coutinho AON. Alimentação do brasileiro: "Uma visão histórica”. Saúde debate. 1988; 32-39.

60. Castro CM, Coimbra M. Problema alimentar no Brasil. São Paulo: Almed; 1985.

61. Burlandy L, Bodstein RC. Política e saúde coletiva: reflexão sobre a produção científica (1976-1992). Cad. Saúde Pública. 1998; 14(3):543-554.

Recebido em 28/12/2019 Aprovado em 07/09/2020

Conflito de interesses: inexistente

Suporte financeiro: não houve 